\title{
GAS CHROMATOGRAPHIC STUDIES OF THE RELATIVE RETENTION OF THE SULFUR ISOTOPES IN CARBONYL SULFIDE, CARBON DISULFIDE, AND SULFUR DIOXIDE
}

TECHNICAL REPORT SUBMITTED FOR REVIEW

18 JANUARY 1980

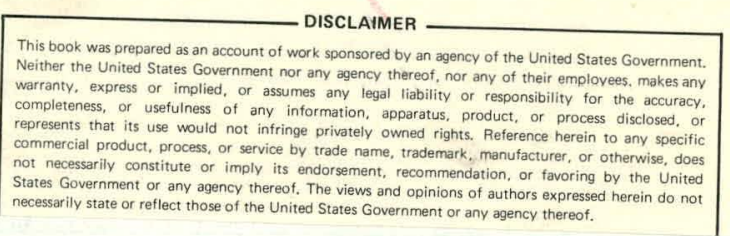

J. C. FETZER AND L. B. ROGERS

DEPARTMENT OF CHEMISTRY

UNIVERSITY OF GEORGIA

ATHENS, GEORGIA 30602

\author{
PREPARED FOR THE \\ U.S. DEPARTMENT OF ENERGY \\ ASSISTANT SECRETARY FOR ENERGY TECHNOLOGY \\ OFFICE OF ENERGY RESEARCH \\ UNDER CONTRACT DE-AS09-76ER00854
}




\section{DISCLAIMER}

This report was prepared as an account of work sponsored by an agency of the United States Government. Neither the United States Government nor any agency Thereof, nor any of their employees, makes any warranty, express or implied, or assumes any legal liability or responsibility for the accuracy, completeness, or usefulness of any information, apparatus, product, or process disclosed, or represents that its use would not infringe privately owned rights. Reference herein to any specific commercial product, process, or service by trade name, trademark, manufacturer, or otherwise does not necessarily constitute or imply its endorsement, recommendation, or favoring by the United States Government or any agency thereof. The views and opinions of authors expressed herein do not necessarily state or reflect those of the United States Government or any agency thereof. 


\section{DISCLAIMER}

Portions of this document may be illegible in electronic image products. Images are produced from the best available original document. 
This report was prepared as an account of work sponsored by an agency of the United States Government. Neither the United States Government nor any agency thereof, nor any of their employees, makes any warranty, express or implied, or assumes any legal liability or responsibility for the accuracy, completeness, or usefulness of any information, apparatus, product, or process disclosed, or represents that its use would not infringe privately owned rights. Reference herein to any specific commercial product, process, or service by trade name, trademark, manufacturer, or otherwise, does not necessarily constitute or imply its endorsement, recommendation, or favoring by the United States Government or any agency thereof. The views and opinions of authors expressed herein do not necessarily state or reflect those of the United States Government or any agency thereof.

Available from

National Technical Information Service

U.S. Department of Commerce

5265 Port Royal Road

Springfield, Virginia 22161

Price: Code $\mathrm{AO} 2$

Microfiche: Price Code A01

Printed in the United States of America. 
TABLE OF CONTENTS

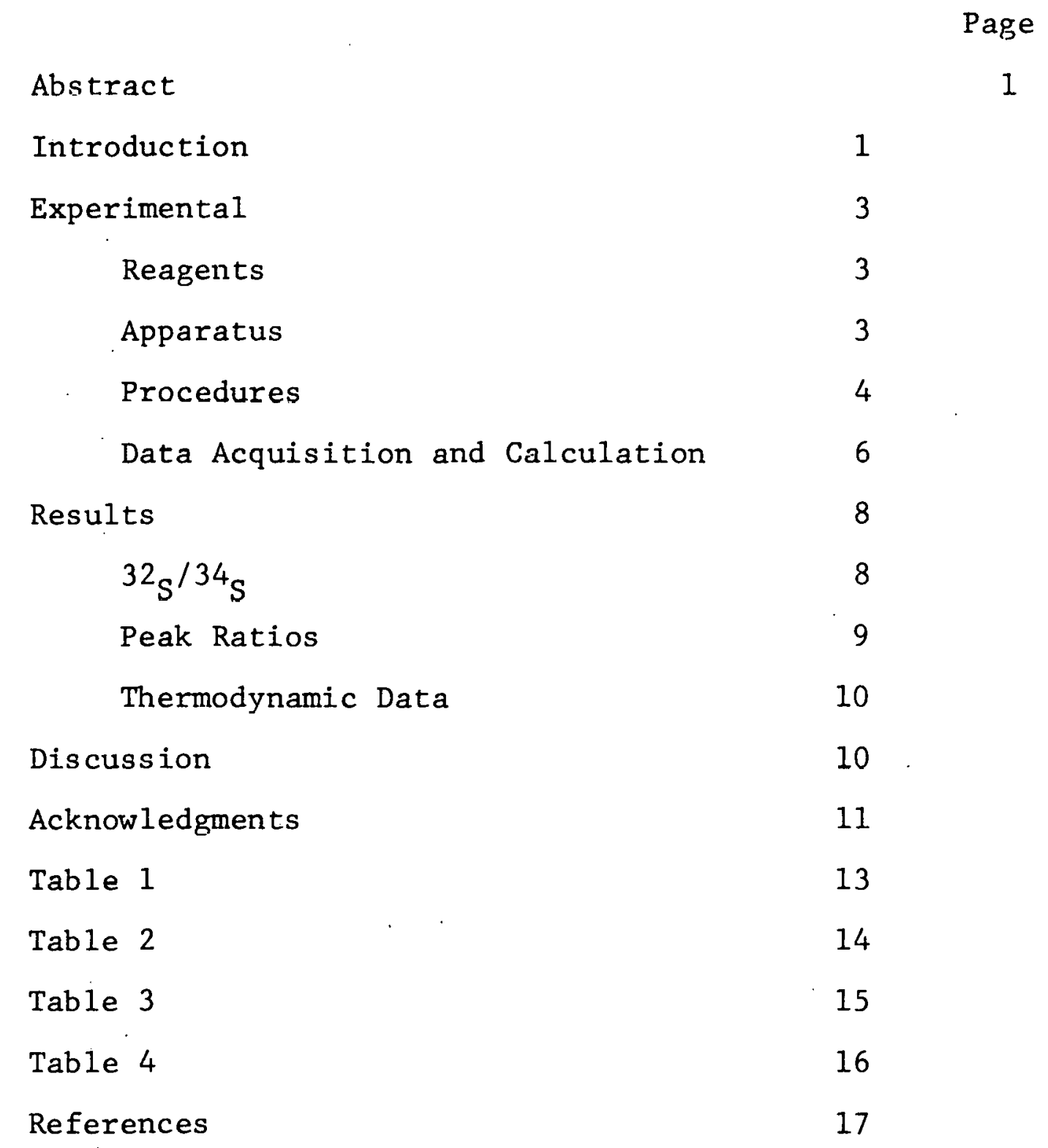


GAS CHROMATOGRAPHIC STUDIES OF THE RELATIVE RETENTION

OF THE SULFUR ISOTOPES IN CARBONYL SULFIDE,

CARBON DISULFIDE, AND SULFUR DIOXIDE

by

J. C. Fetzer and L. B. Rogers

Department of Chemistry

University of Georgia

Athens, Georgia 30602

\begin{abstract}
A precision gas chromatograph, coupled to a quadrupole mass spectrometer and an on-line computer, was used to study the fractionation on Porasil $\mathrm{A}$ of the ${ }^{32} \mathrm{~S} /{ }^{34} \mathrm{~S}$ isotopic pair in a variety of sulfur-containing molecules. Carbonyl sulfide (COS) yielded an average $\alpha$ value of $1.00074 \pm 0.00017$ (standard deviation) for the temperature range $25^{\circ} \mathrm{C}$ to $75^{\circ} \mathrm{C}$. The carbon disulfide $\left(\mathrm{CS}_{2}\right)$ value was $1.00069 \pm 0.00023$ for the range $53^{\circ} \mathrm{C}$ to $103^{\circ} \mathrm{C}$, and that for sulfur dioxide $\left(\mathrm{SO}_{2}\right)$ was $1.00090 \pm 0.00018$ for the range $62^{\circ} \mathrm{C}$ to $112^{\circ} \mathrm{C}$. Differential thermodynamic data have been reported. A Porapak Q column showed no fractionation of this isotopic pair in these three molecules.
\end{abstract}

\title{
INTRODUCTION
}

Much recent work has been done in the area of stable isotope fractionation studies in gas chromatography. Even though the liydrogen/deutcrium pair remains the most studied (1), several 
articles have dealt with heavier atomic systems. Most of this work has been with the pairs ${ }^{12} \mathrm{C} /{ }^{13} \mathrm{C},{ }^{14} \mathrm{~N} /{ }^{15} \mathrm{~N}$, and ${ }^{16} \mathrm{O} /{ }^{18} \mathrm{O}(2-6)$, with little work having been attempted on systems involving heavier atoms.

Investigation of gas chromatographic fractionation of the sulfur pair, ${ }^{32} \mathrm{~S} /{ }^{34} \mathrm{~S}$, has been limited to $\mathrm{SF}_{6}(7,8)$ and $\mathrm{H}_{2} \mathrm{~S}$ (9). The small molecules carbonyl sulfide (COS), carbon disulfide $\left(\mathrm{CS}_{2}\right)$, and sulfur dioxide $\left(\mathrm{SO}_{2}\right)$ have not been investigated. These would be of interest because of prior work on $\mathrm{CO}_{2}$ (4) and CO (6).

Many of the studies on isotopic fractionation indicate that the magnitude of the fractionation and the trends observed as a function of temperature strongly reflect the interactions of the sample with the chromatographic packing. The sulfur atoms in $\mathrm{COS}, \mathrm{CS}_{2}$, and $\mathrm{SO}_{2}$ are in different chemical environments, and some insight into their adsorption mechanism could be gained by studies of the fractionations of their sulfur isotopes. Also, $\mathrm{COS}$ and $\mathrm{CS}_{2}$ are chemical analogs of $\mathrm{CO}_{2}$, so comparisons of their results with those previously reported for $\mathrm{CO}_{2}$ (4) could be made. Studies of the fractionations of ${ }^{12} \mathrm{C} /$ ${ }^{13} \mathrm{C}$ and ${ }^{16} \mathrm{O} /{ }^{17} \mathrm{O}$ as well as ${ }^{32} \mathrm{~S} /{ }^{33} \mathrm{~S}$ would obviously have been of interest, but mutual interferences prevented these measuremente from being made using a low resnlintion mass spectrometer. Studies on short packed columns of Porasil A and Porapak $Q$ were done to obtain relative retentions and differential thermodynamic data for these molecules. Values for $\Delta\left(\Delta \underline{H}^{\circ}\right)$ and $\Delta\left(\Delta \underline{S}^{\circ}\right)$ 
have been calculated for the ${ }^{32} \mathrm{~S} /{ }^{34} \mathrm{~S}$ fractionation observed. Karger (10) pointed out that such values were expected to be small because of the very small separation factors observed for most isotope pairș.

It is clear that when measuring only the $M$ and $(M+2)$ signals, the contributions of ${ }^{34} \mathrm{~S}$ and ${ }^{18} \mathrm{O}$ will interfere with one another. For that reason, the $(M+2) / M$ ratio was measured as a function of time in each chromatogram so as to obtain an indication of the behavior of the ${ }^{18} 0$ species in $\cos$ and $\mathrm{SO}_{2}$.

\section{EXPERIMENTAL}

\section{Reagents}

Porapak Q (Waters Associates) and Porasil A (Supelco) were used as received. Dichlorodimethylsilane (Pierce Chemical) was used to treat the Watson-Beimann separator, connecting tubing, and gas chromatograph-mass spectrometer interface.

Carbon disulfide (Fisher Scientific), carbonyl sulfide (Matheson Gas Products), sulfur dioxide (Matheson Gas Products), air and argon (Selox) were used as received. Helium (Selox) was purified by passing it through heated $\left(400^{\circ} \mathrm{C}\right)$ copper turnings and Linde molecular sieve 5A (Union Carbide).

\section{Apparatus}

Most of the experimental apparatus has been described previously (4-6). On-line data collection and analysis was performed by a PDP 11/20 minicomputer system (Digital Equipment). 
The gas chromatograph was built in our laboratory from component parts. A Valco Model CV-8HPa pneumatic valve (Valco Instruments) had a $15 \mu 1$ sample loop. A custom-made cylindrical air bath was used for the ambient and elevated temperature studies. A $1700 \mathrm{rpm}$ squirrel cage fan circulated air past a 22 gauge Nichrome heating element. Temperatures were regulated using a Melabs Model CTC-1A proportional controller (Melabs) and mounted $\mathrm{MH}$ series Stikon thermometers (RdF). Temperatures were stable to $\pm 0.03^{\circ} \mathrm{C}$. All electronics for the gas chromatograph, as well as the carrier-gas conditioning columns, were maintained at $35 \pm 0.4^{\circ} \mathrm{C}$ to increase stability. Carrier gas flow rates were maintained constant within $\pm 0.2 \%$ using a Brooks Model 5840 controller.

The mass spectrometer (UTI Model 100C) was controlled by a PDP $11 / 20$ computer. Mass-to-charge ratios were selected through a 14-bit digital-to-analog converter (Analog Devices Model 14QM). The output signal was transferred through an 8-bit latch (4) to a Beckman Model 3700 ANSCAN analog-to-digital converter. Individual chromatograms were stored on DECtape (Digital Equipment).

\section{Procedures}

Column lengths and operating temperatures were chosen so that the sulfur-containing molecules had relative retention times of 10 to 15 minutes. This resulted in a $3.0 \mathrm{~m}$ Porapak $Q$ column being used, and Porasil A columns of $0.75 \mathrm{~m}$ (COS), 
$1.5 \mathrm{~m}\left(\mathrm{CS}_{2}\right)$, and $5.8 \mathrm{~m}\left(\mathrm{SO}_{2}\right)$ length. Columns were constructed from $2.2 \mathrm{~mm}$ i.d. 316 stainless steel tubing that had been successively washed with methanol, chloroform, and acetone after silanization with a $20 \%$ solution of dichlorodimethylsilane in toluene.

All columns were dry packed using the "tap and fill" method. The Porapak $Q$ column was conditioned by heating at $250^{\circ} \mathrm{C}$ with a helium flow of $5 \mathrm{ml} / \mathrm{min}$ for 8 hours. Porasil A columns were conditioned at $350^{\circ} \mathrm{C}$ under otherwise the same conditions. Argon was used throughout these studies as the non-retained species, and it was monitored by observing the output signal at m/e 40. Sample mixtures were 4:1 sample-to-argon pressure ratios for carbonyl sulfide and sulfur dioxide. (Preliminary studies showed no change in retention time for different sample mixtures.) Being a liquid at room temperature, carbon disulfide had to be injected differently. It was loaded into the sample loop by passing air through a fritted glass bubbler. The argon in the air was monitored, rather than spiking the sample with it. The optimum flow rate for each system was estimated from a Van Deemter plot at the first temperature studied. A period of 2 hours was allowed for thermal equilibration before each experiment.

The vacuum in the mass spectrometer was monitored by a NRC Mode1 836 (Varian Associates). An inlet pressure of $3 \mathrm{x}$ $10^{-6}$ torr was found fo give the largest signal with no peak broadening. (Broadening was observed at higher inlet pressures.) 
Data Acquisition and Calculation

Selective ion monitoring was used for data acquisition. Chromatograms for each mass were collected by alternately monitoring the desired masses. The Beckman Anscan took 5 values, each 1 millisecond apart, for each of the 240 data points in the chromatogram for each mass. The collection rate was two points per second for each mass. A minimum of sixteen replicates were run at each temperature.

Peak locations were calculated by using a 21-point curve fit around the highest data point in each peak. Gram polynomials (12) were used for the fit. The retention time, $\underline{t}_{\underline{r}}$, was defined as the difference between the calculated peak maximum and the injection time. The $\underline{t}_{\underline{r}}$ for the second mass was also corrected to allow for the delay due to data acquisition and reading.

Studies of the other isotopic species in these molecules $\left({ }^{13} \mathrm{C},{ }^{17} \mathrm{O},{ }^{18} \mathrm{O}\right.$, and $\left.{ }^{33} \mathrm{~S}\right)$ were not possible because they interfered with one another due to their similar natural abundances. Peak-ratio monitoring $(8,11)$ was used, however, to see if ${ }^{18} 0$ interfered with the ${ }^{34} \mathrm{~S}$ signal. Tha ratio of the $M$ and $(M+2)$ peaks should be a constant if they are superimposed, assuming that the two isotopes undergo similar interactions. The magnitude of the adsorption energies, relative to the small difference due to isoțopic substitution, is large enough to ensure similar peak shapes. If ${ }^{18} 0$ has an observable effect the $(M+$ 2) peak shape will be different than that of the M peak. This 
will occur when the ${ }^{18} 0$ species has a different retention time than the ${ }^{34} \mathrm{~S}$ species. $\left({ }^{34} \mathrm{~S}\right.$ is present as 4.22 percent of the sulfur atoms, and ${ }^{18} 0$ is present as 0.20 percent of the oxygen atoms, so ${ }^{18} 0$ should be observable by our apparatus since it would comprise 5 percent of the $(M+2)$ signal for $\operatorname{COS}$ and 10 percent of that for $\mathrm{SO}_{2}$.)

Calculation of thermodynamic values from chromatographic data has been reviewed (10). In the present studies the relative retention, $\alpha$, was calculated as:

$$
\alpha=\left(\underline{t}_{\underline{r}_{2}}-\underline{t}_{\underline{a}}\right) /\left(\underline{t}_{\underline{r}_{1}}-\underline{t}_{\underline{a}}\right)=\underline{K}_{\underline{2}} / \underline{K}_{\underline{1}}
$$

where $\underline{t}_{\underline{r}_{1}}$ and $\underline{t}_{\underline{r}_{2}}$ are uncorrected retention times, $\underline{t}_{\underline{a}}$ is the retention time of the nonretained species (argon in this case), and $\underline{K}_{1}$ and $\underline{K}_{2}$ are distribution ratios. An indiviaual a value was calculated for each run so as to minimize effects of variations in temperature and flow between runs.

Differential standard molar free energies were calculated from

$$
\Delta\left(\Delta \underline{G}^{\mathrm{O}}\right)=-\underline{\mathrm{RT}} \ln \alpha
$$

where $\underline{R}$ is the gas constant, and $\underline{T}$ is the absolute temperature. A linear least squares analysis of ln a versus $1 / \underline{T}$ was used
to calculate $\Delta\left(\Delta \underline{H}^{\circ}\right)$ and $\Delta\left(\Delta \underline{S}^{\circ}\right)$ values from 


$$
\ln \alpha=-\frac{\Delta\left(\Delta \underline{\mathrm{H}}^{\mathrm{O}}\right)}{\underline{\mathrm{RT}}}+\frac{\Delta\left(\Delta \underline{\mathrm{S}}^{\mathrm{O}}\right)}{\underline{\mathrm{R}}}
$$

\section{RESULTS}

${ }^{32} \mathrm{~s} /^{34} \mathrm{~s}$

In preliminary studies Porapak $Q$ showed no significant fractionating capability for the sulfur isotopes in these molecules. For $\cos$, there might have been a small effect because the $\alpha$ values for ${ }^{34} \mathrm{~S} /{ }^{32} \mathrm{~S}$ had an average of $1.00022 \pm 0.00017$ for the temperature range $24.27^{\circ} \mathrm{C}$ to $65.31^{\circ} \mathrm{C}$.

Adsorption chromatography on Porasil A yielded measureable fractionations for all three molecules. The values obtained for carbonyl sulfide are given in Table 1 . Retention times decreased from 990 to 600 seconds as the temperature was raised. Peak widths, measured at half height, decreased from 60 seconds to 25 seconds. The actual difference in the calculated maxima changed from 0.85 to 0.30 seconds. For carbonyl sulfide, a normal isotopic effect was observed; that is, the 1 ighter ${ }^{32} \mathrm{~S}$ species eluted before the heavier ${ }^{34} \mathrm{~S}$.

Carbon disulfide, a chemical analog of carbonyl sulfide, also showed a normal isotope effect. Relative retention and differential standard free energy values for carbon disulfide are given in Table 2. Relative retentions decreased from 1150 to 750 seconds as the temperature increased. Peak widths changed from 80 to 45 seconds, while separations of peak maxima went from 0.87 to 0.54 seconds. The slightly larger standard deviations of carbon disulfide, compared to those of carbonyl sulfide, 
resulted from the smaller amount of adsorbate that could be injected as a result of bubbling air through liquid $\mathrm{CS}_{2}$ instead of injecting pure $\mathrm{CS}_{2}$. This disadvantage was partially offset by the doubled isotopic abundance of ${ }^{34} \mathrm{~S}$ in carbon disulfide. Sulfur dioxide showed a different behavior than the other two molecules. It had an inverse isotopic effect, the heavier ${ }^{34} \mathrm{~S}$ species eluted before the ${ }^{32} \mathrm{~S}$ species. The retention times for $\mathrm{SO}_{2}$ decreased from 900 to 540 seconds as the temperature was raised, while peak widths decreased from 95 to 40 seconds. The separations of the peak maxima changed from 0.93 to 0.40 seconds.

The smaller standard deviations obtained in this work compared to those in previous studies $(4,5,6)$ resulted primarily from the use of signal averaging and a faster data-acquisition cycle.

\section{Peak Ratios}

For the oxygen-containing molecules, peak ratios of the chromatograms were obtained. For both carbonyl sulfide and sulfur dioxide the signal due to ${ }^{18} \mathrm{O}$ was detected in the $\mathrm{M}+$ 2) chromatogram. In carbonyl sulfide, ${ }^{12} \mathrm{C}^{18} \mathrm{O}^{32} \mathrm{~S}$ eluted approximately 0.6 to 0.7 seconds after ${ }^{12} \mathrm{C}^{16} \mathrm{O}^{32} \mathrm{~S}$ at the lower temperatures, and ${ }^{12} \mathrm{C}^{16} \mathrm{O}^{34} \mathrm{~S}$ eluted 0.2 to 0.3 seconds later. The ${ }^{18} \mathrm{O}$ species in sulfur dioxide also eluted between the ${ }^{32} \mathrm{~S}$ and ${ }^{34} \mathrm{~S}$ species, but since $\mathrm{SO}_{2}$ had an inverse effect the order was ${ }^{34} \mathrm{~s}^{16} \mathrm{O}^{16} \mathrm{O},{ }^{32} \mathrm{~s}^{18} \mathrm{O}^{16} \mathrm{O},{ }^{32} \mathrm{~s}^{16} \mathrm{O}^{16} \mathrm{O}$. The ${ }^{18} \mathrm{O}$ species eluted about 0.1 to 0.2 seconds after the ${ }^{34} \mathrm{~S}$ species. 
Thermodynamic Data

Values of $\Delta\left(\Delta \underline{H}^{\circ}\right)$ and $\Delta\left(\Delta \underline{S}^{\circ}\right)$ were calculated using Equation 3. The linear least-squares fits of the data in Tables 1,2 , and 3 yielded the values given in Table 4 . These values are only approximate because the changes in the relative retentions with changes in temperature were not much larger than the standard deviations.

\section{DISCUSSION}

Isotopic fractionation of the sulfur isotopes was observed in carbonyl sulfide, carbon disulfide, and sulfur dioxide on Porasil A but not on Porapak Q. For the latter, no observable fractionation for carbonyl sulfide and carbon disulfide would be expected if the interaction were through the carbon atoms. However, sulfur dioxide also showed no fractionation, which could imply that all three molecules were oriented flat on the surface. This would minimize the sulfur isotope effect.

The fractionations on Porasil A were temperature dependent. The linearity of the plots of $\ln \alpha$ versus $1 / \underline{T}$ indicated that only one mechanism of adsorption was likely. A trend was observed when comparisons were made between the results for carbunyl sulflde and carbon disulfide and those previously reported for carbon dioxide (4). All three showed isotopic fractionation in the "normal" order. The smaller $\alpha$ values observed for the sulfur isotope pair reflected the weaker interaction and the smaller relative difference in the electron levels of 
sulfur isotopes compared to oxygen isotopes. The positive $\Delta\left(\Delta \underline{S}^{\circ}\right)$ value for carbon disulfide indicates that Porasil A prefers the lighter ${ }^{32} \mathrm{~S}$ species, the negative values for carbonyl sulfide and carbon dioxide (4) indicate a preference for the heavier isotope species.

The larger a values found for sulfur dioxide reflected its much stronger interaction with the silica packing. Its inverse isotopic effect indicates the interactions with its sulfur atoms are much different from those in the other molecules, since Porasil A was used for studies of all three molecules.

The results obtained in this study showed that for heavy atoms, such as sulfur, an isotopic effect could be observed using gas chromatography even though the observed isotopic differences were much smaller than those reported in previous work in this field. The use of peak ratios to check for interferences from less abundant isotopes has been shown to be useful in cases where one interfering isotope is much more abundant than another.

\section{ACKNOWLEDGMENTS}

The authors wish to acknowledge the assistance of P. A. Bloxham and M. S. Klee in preliminary development of the programs used. This work was supported by the Division of Basic Energy Sciences of the Department of Energy through Contract No. DE-AS09-76ER00854. We also wish to acknowledge the support 
from the University of Georgia in the form of a Graduate Assistantship (J, C. F.). 
Table 1

Relative Retention and $\Delta\left(\Delta \underline{G}^{\circ}\right)$ as a Function of Temperature for the Sulfur Isotope Pair in Carbonyl Sulfide on Porasil A

T, ${ }^{\circ} \mathrm{C}$

24.31

28.26

33.14

37.66

42.82

46.73

50.78

54.42

58.27

62.19

65.29

70.32

73.75

$$
\alpha\left({ }^{34} s /{ }^{32} s\right)
$$

$1.00085 \pm 0.00014$

$1.00088 \pm 0.00017$

$1.00081 \pm 0.00020$

$1.00078 \pm 0.00017$

$1.00077 \pm 0.00011$

$1.00071 \pm 0.00015$

$1.00078 \pm 0.00021$

$1.00072 \pm 0.00012$

$1.00071 \pm 0.00016$

$1.00066 \pm 0.00019$

$1.00064 \pm 0.00021$

$1.00068 \pm 0.00022$

$1.00065 \pm 0.00015$
$\Delta\left(\Delta \underline{G}^{\circ}\right) \mathrm{J} \mathrm{mol}^{-1}$

$-2.10$

$-2.20$

$-2.06$

$-2.02$

$-2.02$

$-1.89$

$-2.10$

$-1.96$

$-1.96$

$-1.84$

$-1.80$

$-1.94$

$-1.87$ 
Table 2

Relative Retentions and $\Delta\left(\Delta \underline{G}^{\circ}\right)$ as a Function of Temperature for the Sulfur Isotopic Pair

Carbon Disulfide on Porasil A

$\begin{array}{ccc}\underline{\mathrm{T}}\left({ }^{\circ} \mathrm{C}\right) & \alpha\left({ }^{34} \mathrm{~S} /{ }^{32} \mathrm{~S}\right) & \Delta\left(\Delta \underline{G}^{0}\right)(\mathrm{J} \mathrm{mol} \\ 53.87 & 1.00076 \pm 0.00029 & -2.07 \\ 58.56 & 1.00078 \pm 0.00026 & -2.15 \\ 62.96 & 1.00081 \pm 0.00023 & -2.26 \\ 67.52 & 1.00077 \pm 0.00019 & -2.18 \\ 72.68 & 1.00074 \pm 0.00023 & -2.13 \\ 76.59 & 1.00073 \pm 0.00021 & -2.18 \\ 80.70 & 1.00069 \pm 0.00026 & -2.03 \\ 84.32 & 1.00072 \pm 0.00022 & -2.14 \\ 87.89 & 1.00074 \pm 0.00027 & -2.22 \\ 91.59 & 1.00072 \pm 0.00018 & -2.18 \\ 95.11 & 1.00073 \pm 0.00023 & -2.23 \\ 99.92 & 1.00076 \pm 0.00026 & -2.36 \\ 103.48 & 1.00072 \pm 0.00021 & -2.19\end{array}$


Table 3

Relative Retentions and $\Delta\left(\Delta \underline{G}^{\circ}\right)$ as a Function of Temperature for the Sulfur Isotopic Pair, in Sulfur Dioxide on Porasil A

$\begin{array}{ccc}\underline{\mathrm{T}}\left({ }^{\circ} \mathrm{C}\right) & \alpha\left({ }^{32} \mathrm{~S} /{ }^{34} \mathrm{~S}\right) & \Delta\left(\Delta \underline{G}^{0}\right)\left(\mathrm{J} \mathrm{mol}{ }^{-1}\right) \\ 61.79 & 1.00103 \pm 0.00021 & -2.87 \\ 65.47 & 1.00105 \pm 0.00013 & -2.96 \\ 69.97 & 1.00098 \pm 0.00024 & -2.79 \\ 73.75 & 1.00101 \pm 0.00017 & -2.91 \\ 77.86 & 1.00095 \pm 0.00022 & -2.77 \\ 82.32 & 1.00093 \pm 0.00020 & -2.75 \\ 86.63 & 1.00091 \pm 0.00015 & -2.72 \\ 90.08 & 1.00087 \pm 0.00019 & -2.63 \\ 94.88 & 1.00084 \pm 0.00021 & -2.57 \\ 98.82 & 1.00085 \pm 0.00018 & -2.63 \\ 102.40 & 1.00079 \pm 0.00013 & -2.47 \\ 107.16 & 1.00071 \pm 0.00016 & -2.24 \\ 111.48 & 1.00074 \pm 0.00017 & -2.37\end{array}$




$$
\begin{gathered}
\text { Table } 4 \\
\Delta\left(\Delta \underline{H}^{\circ}\right) \text { and } \Delta\left(\Delta \underline{S}^{\circ}\right) \text { for the Fractionations } \\
\text { Observed on Porasil A }
\end{gathered}
$$

$\begin{array}{lcc} & \Delta\left(\Delta \underline{\mathrm{H}}^{\mathrm{O}}\right) \mathrm{J} \mathrm{mol}^{-1} & \Delta\left(\Delta \underline{S}^{\mathrm{O}}\right) \mathrm{J} \mathrm{mol}^{-1} \\ \text { Carbonyl Sulfide } & -3.87 & -5.84 \times 10^{-3} \\ \text { Carbon Disulfide } & -8.75 & +2.58 \times 10^{-3} \\ \text { Sulfur Dioxide } & -7.02 & -1.21 \times 10^{-2}\end{array}$




\section{REFERENCES}

1. G. Jarisco and A. Van Hook, Chem. Rev., 74, 743 (1974).

2. G. Cartoni and M. Possanzini, J. Chromatogr., 39, 99 (1969).

3. F: Bruner, G. Cartoni, and A. Liberti, Anal. Chem., 38, 298 (1966).

4. A. T. Shepard, N. D. Danielson, R. E. Pauls, N. H. Mahle, P. J. Taylor, and L. B. Rogers, Sep. Sci. Tech., 11, 279 (1976).

5. R. E. Pauls, N. H. Mahle, A. T. Shepard, J. C. Gaw, and

L. B. Rogers, Sep. Sci. Tech., 12, 307 (1977).

6. J. C. Fetzer, P. A. Bloxham, and L. B. Rogers, Accepted by Sep. Sci. Tech., 1979.

7. E. Bayer, G. Nicholson, and R. Sievers, J. Chromatogr. Sc1., 8, 467 (1970).

8. N. Moiseyev and I. Platzner, J. Chromatogr. Sci., 14, 143 (1976).

9. A. A. Postnikov, A. E. Kovalenko, and Y. D. Zel'Venskii, Deposited Doc., Viniti, 1626-75, 26-32 (1975), found ChemIcal Abstract, $82,108135 \mathrm{~L}$.

10. B. L. Karger, Anal. Chem., 39, 24A (1967).

11. R. H. Betts and W. D. Buchanon, Can. J. Chem., 54, 3007 (1976).

12. H. T. Davis, "Tables bf Mathematical Functions, Vo1. 2," Principia, San Antonio, Texas, 1963, p.307. 